\title{
Comparing Hospital-Based Resource Utilization and Costs for Prostate Cancer Patients With and Without Bone Metastases
}

\author{
Brian Seal $\cdot$ Sean D. Sullivan $\cdot$ Scott D. Ramsey $\cdot$ Carl V. Asche $\cdot$ \\ Ken Shermock · Syam Sarma $\cdot$ Erin A. Zagadailov • \\ Eileen Farrelly $\cdot$ Michael Eaddy
}

Published online: 9 July 2014

(c) The Author(s) 2014. This article is published with open access at Springerlink.com

\begin{abstract}
Background Since 2010, several new treatments for prostate cancer $(\mathrm{PCa})$, which have entered the US market, are poised to have an impact on treatment approaches; however, there is a paucity of evidence with respect to treatment patterns and costs. As new treatment patterns emerge, it will be imperative to understand treatment patterns and costs of care prior to the advent of novel treatments.

Objective As the PCa treatment landscape is evolving, this study sought to compare the hospital-based utilization and costs in two cohorts of patients with PCa: patients with bone metastases $(\mathrm{w} / \mathrm{BM})$ and patients without bone
\end{abstract}

Previous presentation: Parts of these results were presented at ISPOR International Conference in Washington, DC, in May 2012 (Poster \#PCN51). This paper expands upon and adds to that analysis.

Electronic supplementary material The online version of this article (doi:10.1007/s40258-014-0101-1) contains supplementary material, which is available to authorized users.

\section{B. Seal}

Bayer HealthCare Pharmaceuticals, Whippany, NJ, USA

e-mail: brian.seal@bayer.com

\section{S. D. Sullivan}

University of Washington, Seattle, WA, USA

e-mail: sdsull@u.washington.edu

\section{S. D. Ramsey}

Fred Hutchinson Cancer Research Center, Seattle, WA, USA

e-mail: sramsey@fhcrc.org

C. V. Asche

University of Illinois College of Medicine, Peoria, IL, USA

e-mail: cva@uic.edu

\section{K. Shermock}

The Johns Hopkins University, Baltimore, MD, USA

e-mail: kenneth@jhmi.edu metastases (w/oBM). Comparisons were also made for patients with inpatient versus outpatient encounters.

Methods Patients in the Premier Perspective Database, a US hospital database, between January 2006 and December 2010, treated in an inpatient or outpatient setting for PCa (International Classification of Diseases, 9th Revision [ICD-9] diagnosis codes 185, 233.4) were included. Patients were required to be $\geq 40$ years of age with no additional cancers. Patients were put into cohorts on the basis of the presence of bone metastases (ICD-9 code 198.5 or use of zoledronic acid or pamidronate disodium). Utilization of PCa-related treatments was compared, controlling for age, race, hospital type, payer type, bed size, and admission source and type. Differences in treatments were assessed utilizing logistic regression, while differences in costs were analyzed using gamma-distributed generalized linear models with a log-link function. All costs are reported in US\$2010.

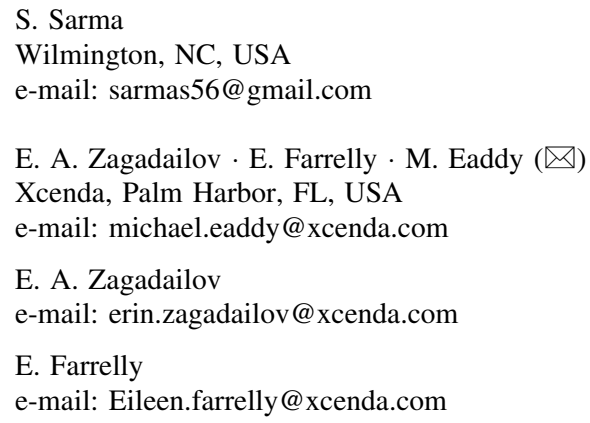


Results There were 23,747 hospitalizations for men w/BM (13,716 inpatient; 10,031 outpatient) and 187,708 hospitalizations (74,435 inpatient; 113,258 outpatient) for men w/oBM. The mean length of stay for men w/BM was 4 days compared with 2 days for men w/oBM $(P<0.0001)$. Overall, the mean cost per encounter was US\$9,728 in men with $\mathrm{w} / \mathrm{BM}$ and US\$7,405 in men w/oBM $(P=0.0006)$. For inpatient stays, the mean cost per encounter was US\$14,145 for men w/BM and US\$11,944 for men w/oBM. For outpatient visits, the mean cost per encounter was US\$3,688 for men w/BM and US $\$ 4,422$ for men w/oBM. Men w/BM received hormone therapy $(44.3 \%)$ and secondary hormone therapy $(46.4 \%)$ most often, while men w/oBM received radiation $(48.8 \%)$ and surgery $(31.9 \%)$ most often.

Conclusion Costs and utilization of PCa-related treatments vary on the basis of the presence of metastases and treatment setting (inpatient vs. outpatient).

\section{Key Points for Decision Makers}

Inpatient hospital care plays a significant role in men with prostate cancer with bone metastasis.

This study highlights to decision makers the differences in the cost of treating men with prostate cancer with and without bone metastases and provides a context for future trends, given new therapeutic options.

\section{Introduction}

Prostate cancer ( $\mathrm{PCa}$ ) is the most commonly diagnosed cancer in men in the USA, and is ranked the second most common cancer in terms of cancer-related mortality [1]. It is estimated that more than 241,700 new cases of PCa will be diagnosed in 2012 (29\% of all cancer diagnoses), resulting in more than 28,170 PCa-related deaths (9\% of all cancer deaths) in the USA [2].

Approximately $95 \%$ of patients with PCa are diagnosed when asymptomatic in early disease stages. These patients have a 5-year survival rate of $100 \%$ [3]. Since early disease is considered curative, its management is individualized [4]. Therapy options include surgery such as radical prostatectomy (RP); radiation therapy (RT), mainly external beam RT and brachytherapy; or watchful waiting (delaying therapy until progressive or symptomatic disease) [4]. In addition, androgen deprivation therapy (ADT) may be combined with RT in patients who have a high risk for recurrence [4].
In contrast, approximately $4 \%$ of patients have metastatic prostate cancer (MPC) [3] upon diagnosis. These patients have an unfavorable 5-year survival rate of about $28 \%[3,5]$. The treatment of advanced $\mathrm{PCa}$ is palliative; the first-line treatment option is ADT [4]. The majority of MPC patients subsequently develop castration-resistant prostate cancer (CRPC), defined as successive prostatespecific antigen (PSA) increases and/or disease progression despite castrate testosterone levels [6, 7]. Salvage treatment options for CRPC include enrollment in a clinical trial, secondary hormonal therapy (abiraterone acetate and enzalutamide), immunotherapy (sipuleucel-T), and chemotherapy (docetaxel and cabazitaxel) [4].

These salvage therapies have shown substantial survival gains in post-docetaxel patients with CRPC and bone metastases, ranging from 2.4-4.8 months for cabazitaxel [8], abiraterone [9], and enzalutamide [10] in the symptomatic population and 4.1 months for sipuleucel-T in the asymptomatic/minimally symptomatic population [11]. Abiraterone has also shown an overall survival (OS) benefit in predocetaxel patients with CRCP and bone metastases on the basis of the interim results from a phase III study [12].

However, these survival benefits come at a considerable price. For example, the cost of 3 cycles of sipuleucel-T, based on the wholesale acquisition cost published in Red Book, is an estimated US\$93,000, while secondary hormonal therapies, such as prednisone, are available generically and are relatively inexpensive for the treatment of symptomatic patients with CRPC [13]. For comparison, the cost for 6 cycles of docetaxel is over US\$14,000, and for cabazitaxel, over US\$38,000 [13]. These costs will increase further when these new agents are incorporated into earlier lines of therapy, as these new agents are expected to have larger survival gains in the less pre-treated cohort [6].

Bone is the most common metastatic site specific to PCa-related metastases. The majority of patients (80-90 \%) with CRPC have osteoblastic lesions and, less frequently, osteolytic lesions [14, 15]. As a consequence, skeletal-related events (SREs) such as fractures and bone pain develop in these patients, who subsequently require RT or surgery [16].

The use of bone-targeting agents (e.g., zoledronic acid, denosumab) is supported to prevent or delay PCa-associated SREs [4]. RT is regarded as a palliative intervention for painful bone metastases [4, 17]. Radiopharmaceuticals are recommended for patients with multifocal bone pain, particularly if they are no longer eligible for chemotherapy [18]. The two most commonly used radiopharmaceuticals for PCa, strontrium-89 $\left({ }^{89} \mathrm{Sr}\right)$ and samarium-153 $\left({ }^{153} \mathrm{Sm}\right)$, are classified as $\beta$-emitting agents [19]. Unfortunately, both agents can cause substantial myelosuppression, thus prohibiting their use in patients with inadequate bone marrow function. 
Radium-223, a novel $\alpha$-emitting radiopharmaceutical, targets bone metastases with high-energy, short-range irradiation, thus preserving bone marrow and limiting penetration to adjacent tissues [20]. Radium-223 has been shown to delay the time to first on-study SRE and improve OS [21]. Enzalutamide, an androgen receptor-signaling inhibitor, has also demonstrated benefits in SREs and OS outcomes in patients with bone metastases [22]. Radium223 was recently approved by the US Food and Drug Administration for the treatment of patients with CRPC with symptomatic bone metastases and no known visceral metastases, and enzalutamide was approved for the treatment of CRPC post-docetaxel.

A growing body of clinical evidence in support of highly effective agents in PCa may lead to a trend in multimodal therapy, particularly with bone-targeted agents. In advanced $\mathrm{PCa}$, healthcare decision makers can expect a considerable component of care to be provided in the inpatient and outpatient hospital settings. Given the changing landscape of PCa treatment, this study sought to provide a unique and informative perspective by capturing the current level of utilization and costs associated with bone metastases (w/BM) compared with those in the absence of bone metastases (without [w/oBM]) in the inpatient and outpatient settings.

\section{Methods}

\subsection{Data Source}

Hospital claims data from the Premier Perspective Database were used to conduct the analyses. This database is the largest hospital database in the USA for determining hospital quality benchmarking and contains linked, deidentified inpatient medical, pharmacy, and billing data from more than 500 geographically dispersed acute care hospitals. Participating hospitals represent all regions of the USA, including predominantly small- to medium-sized non-teaching facilities serving largely urban populations. The database includes information regarding all hospitalbased encounters, including inpatient stays and outpatient visits. The database also contains a date-stamped log of all billed items (including medications, laboratory and diagnostic services), as well as primary and secondary diagnoses for each patient.

\subsection{Sample Selection}

Patients diagnosed with PCa (International Classification of Diseases, 9th Revision [ICD-9] diagnosis codes 185.xx, 233.4) and receiving hospital-based services between 2006 and 2010 were eligible for study inclusion. Patients were required to be $\geq 40$ years old and to have received $\geq 1 \mathrm{PCa}$ related treatment during an encounter. PCa treatment was defined as the presence of a code or claim for prostate surgery, RT, chemotherapy, hormonal therapy, radiopharmaceuticals, or other treatments for PCa. Other treatments for $\mathrm{PCa}$ were defined as pharmacotherapy treatments used to treat $\mathrm{PCa}$ that are not considered chemotherapy or primary hormone therapy, such as ketoconazole or corticosteroids.

Patients diagnosed with a cancer other than PCa were excluded (ICD-9 140.xx-172.xx; 174.xx-184.xx; 186.xx; 187.xx; 189.xx-195.xx; and 199.xx-208.xx). Since patients with PCa may have other distant metastases, patients with a diagnosis of 198.xx (secondary malignant neoplasm of other specified sites) who also had a diagnosis of PCa were not excluded. Patients meeting all criteria were then placed into the two cohorts on the basis of diagnosis codes (ICD-9 code 198.5) or medications (zoledronic acid or pamidronate disodium) indicative of bone metastases.

\subsection{Analysis of Outcomes}

The primary variables of interest were treatments utilized, the corresponding costs of treatments per encounter, and length of stay (LOS). Costs were initially aggregated by the department billing for services in order to provide a comprehensive description of where they were incurred during treatment. Component costs for PCa-related treatments were presented after an independent review of detailed cost estimates by a radiation oncologist. Specifically, the corresponding types and costs of chemotherapy, surgery, RT, or nuclear medicine were evaluated. Hormonal therapy was also evaluated and separated into two categories: primary (5 $\alpha$-reductase inhibitors, antiandrogens, and gonadotropinreleasing hormones) and secondary (steroids) hormonal therapy.

Descriptive summary statistics were constructed as frequencies and proportions for categorical data and means for continuous variables. Differences in baseline demographics between patients $\mathrm{w} / \mathrm{BM}$ and w/oBM were assessed using chi-square tests for categorical variables and $t$ tests for continuous variables. Differences in the percentage of treatments used were assessed utilizing logistic regression, while differences in costs were analyzed using gamma-distributed generalized linear models with a loglink function. All costs are reported in US\$ 2010 and adjusted to 2010 dollars using the medical care component of the Consumer Price Index. Statistical analyses were conducted in SAS version 9.2.1 (SAS Business Analytics, Cary, NC, USA), with an a priori significance level of $\alpha=0.05$. Multivariate analyses of costs and LOS controlled for differences in age, race, payer type, region, 
hospital type, bed size, and admission source. Additional information regarding the analyses may be found in the Electronic Supplementary Material.

\section{Results}

\subsection{Sample Characteristics}

There were 755,375 hospital-based encounters in patients with a diagnosis of PCa. After exclusion criteria were applied (cancer diagnosis other than PCa $4.1 \%$; $<40$ years old $0.11 \%$; female $0.04 \%$; encounter not associated with PCa-related treatment $71 \%$ ), the final sample included 211,440 encounters associated with $\geq 1$ PCa-related treatment. These encounters represented 88,151 inpatient stays and 123,289 hospital-based outpatient visits.

There were 23,747 encounters $(11.23 \%$ ) for $N=11,769$ men $\mathrm{w} / \mathrm{BM}$ and 187,693 encounters $(88.77 \%)$ for $N=109,675$ men w/oBM. The majority of the encounters w/BM (78\%) were associated with a diagnosis code (ICD-9 code 198.5); however, $7 \%$ of encounters w/BM were associated with the use of zoledronic acid or pamidronate disodium, and the remaining $15 \%$ of encounters were associated with both. The mean age of men w/BM was 73 years versus 69 years for men w/oBM and was significantly higher $(P<0.0001)$ (Table 1$)$. Two-thirds of encounters were in Caucasian men (w/oBM $65.7 \%$; w/BM $62 \%$ ), while African American men represented approximately $10 \%$. For both groups, the majority of encounters took place in urban non-teaching hospitals (average bed size 201-400) (Table 1).

Most encounters for men w/oBM occurred in an outpatient setting $(60.3 \%)$, while most encounters for men w/BM occurred in an inpatient setting (57.8 \%). In both groups, the most common encounters were elective-type admissions (73.2\% w/oBM and $40.9 \% \mathrm{w} / \mathrm{BM})$ (Table 1$)$. However, in men w/BM, a significantly higher $(P<0.0001)$ number of encounters were emergency department (38.6 vs. $9.5 \%$ ) and urgent admissions (12.4 vs. $5.1 \%)$.

\subsection{Treatment Utilization}

On average, LOS was 4 days among encounters for men w/BM versus 2 days for men w/oBM $(P<0.0001)$. The longer LOS across all encounters is consistent with the higher proportion of men w/BM that had inpatient stays versus hospital-based outpatient visits. When evaluating inpatient hospitalizations, encounters for men w/BM averaged 3 days longer LOS compared with men w/oBM (7 vs. 4 days). The most common treatment provided for men w/BM was hormonal therapy (primary and secondary). The rates of both primary (44\%) and secondary hormonal therapy (46\%) were significantly higher $(P<0.0001)$ in men w/BM than in men w/oBM (16 and $19 \%$, respectively) (Fig. 1).

Nearly half of encounters for men w/oBM were associated with radiation (49\%), which was significantly higher $(P<0.0001)$ than for men w/BM $(24 \%)$ (Fig. 1). These encounters were more commonly associated with outpatient visits $(79.5 \%)$ than inpatient stays $(1.9 \%)$ (Figs. 2, 3) and were most often brachytherapy related. Overall, very few patients used nuclear medicine; however, the use of nuclear medicine-related $\mathrm{PCa}$ treatments was significantly higher $(P<0.0001)$ in patients w/oBM $(5.2 \%)$ than in those with w/BM (1.2\%) (Fig. 1). In an inpatient setting, patients w/oBM received surgery in two of every three hospital stays (66\%), making surgery the most common procedure in men w/oBM. Furthermore, RP $(22.9 \%)$ and transurethral resection of the prostate (TURP) $(4.1 \%)$ occurred with the highest frequency.

\subsection{Treatment Costs}

The total average cost per encounter in men w/BM and men w/oBM was US\$9,728 and US\$7,405, respectively $(P=0.0006)$ (Table 2). Room and board charges represented $38.9 \%$ of the overall cost for men w/BM (US $\$ 3,788$ per encounter). Room and board and higher pharmacy costs (w/BM US\$2,017 vs. w/oBM US\$551) corresponded with a greater average LOS in men w/BM. In contrast, surgery (US\$1,798), room and board (US\$1,320), and radiation (US $\$ 1,515$ ) were the major cost contributors in men w/oBM.

Surgeries were not common in men w/BM in both treatment settings; however, they were less frequent in the outpatient setting. For men w/oBM, the most common surgery was RP, for which the mean cost was US $\$ 3,714$ across both settings (Table 3). Radiation procedures for men w/oBM ranged from US $\$ 197$ for radioelement handling/loading to US $\$ 2,073$ for external beam RT-related procedures (Table 4). For men w/BM, the least costly radiation procedure was also radioelement handling/loading (average US\$194) and the most costly procedure was interstitial brachytherapy (average US $\$ 1,846$ per procedure). Radiopharmaceuticals ranged from US\$306 for isotope iridium seed to US\$5,814 for isotope palladium seed in men w/oBM (Table 5). Additionally, the vast majority of radiopharmaceuticals were provided to men w/oBM in the outpatient setting.

\section{Discussion}

In this analysis, we compared healthcare resource utilization and costs associated with $\mathrm{PCa}$ w/BM versus w/oBM. 
Table 1 Sample characteristics

\begin{tabular}{|c|c|c|}
\hline & $\begin{array}{l}\text { PCa w/oBM } \\
\left(n^{*}=187,693\right)\end{array}$ & $\begin{array}{l}\mathrm{PCa} \text { w/BM } \\
\left(n^{*}=23,747\right)\end{array}$ \\
\hline \multicolumn{3}{|l|}{ Demographics } \\
\hline Age in years (mean, SD) & 69,10 & 73,10 \\
\hline \multicolumn{3}{|l|}{ Race } \\
\hline African American & $11.8 \%$ & $15.8 \%$ \\
\hline Caucasian & $65.7 \%$ & $62.0 \%$ \\
\hline Hispanic & $2.7 \%$ & $4.3 \%$ \\
\hline Other & $19.8 \%$ & $18.0 \%$ \\
\hline \multicolumn{3}{|l|}{ Treatment setting } \\
\hline Inpatient & $39.7 \%$ & $57.8 \%$ \\
\hline Hospital-based outpatient & $60.3 \%$ & $42.2 \%$ \\
\hline \multicolumn{3}{|l|}{ Payer type } \\
\hline Medicare & $60.1 \%$ & $74.3 \%$ \\
\hline Medicaid & $2.0 \%$ & $4.8 \%$ \\
\hline Commercial/private & $33.5 \%$ & $15.7 \%$ \\
\hline Self-pay & $1.2 \%$ & $2.1 \%$ \\
\hline Other & $3.3 \%$ & $3.1 \%$ \\
\hline \multicolumn{3}{|l|}{ Region } \\
\hline Northeast & $14.1 \%$ & $15.4 \%$ \\
\hline Midwest & $22.7 \%$ & $20.3 \%$ \\
\hline South & $43.3 \%$ & $45.6 \%$ \\
\hline West & $20.0 \%$ & $18.8 \%$ \\
\hline \multicolumn{3}{|l|}{ Hospital type } \\
\hline Urban & $85.2 \%$ & $84.5 \%$ \\
\hline Rural & $14.8 \%$ & $15.6 \%$ \\
\hline Teaching & $39.1 \%$ & $40.6 \%$ \\
\hline Non-teaching & $60.9 \%$ & $59.4 \%$ \\
\hline \multicolumn{3}{|l|}{ Bed size } \\
\hline Average number of beds & 433 & 425 \\
\hline $0-200$ & $10.9 \%$ & $11.9 \%$ \\
\hline $201-400$ & $41.3 \%$ & $39.6 \%$ \\
\hline $401-600$ & $28.2 \%$ & $32.1 \%$ \\
\hline $601-1,000$ & $17.0 \%$ & $14.8 \%$ \\
\hline$>1,000$ & $2.6 \%$ & $1.5 \%$ \\
\hline \multicolumn{3}{|l|}{ Admission source } \\
\hline Physician referral & $76.7 \%$ & $51.5 \%$ \\
\hline Clinic referral & $5.7 \%$ & $3.1 \%$ \\
\hline Transfer from a hospital & $0.7 \%$ & $2.6 \%$ \\
\hline $\begin{array}{l}\text { Transfer from another healthcare } \\
\text { facility }\end{array}$ & $0.6 \%$ & $1.7 \%$ \\
\hline Emergency room & $9.0 \%$ & $36.0 \%$ \\
\hline Other & $7.4 \%$ & $5.0 \%$ \\
\hline \multicolumn{3}{|l|}{ Admission type } \\
\hline Emergency department & $9.5 \%$ & $38.6 \%$ \\
\hline Urgent & $5.1 \%$ & $12.4 \%$ \\
\hline Elective & $73.4 \%$ & $40.9 \%$ \\
\hline Other & $12.0 \%$ & $8.2 \%$ \\
\hline \multicolumn{3}{|l|}{ Primary admitting diagnosis } \\
\hline Prostate cancer (185.xx, 233.4) & $63.0 \%$ & $23.9 \%$ \\
\hline
\end{tabular}

Table 1 continued

\begin{tabular}{lll}
\hline & $\begin{array}{l}\text { PCa w/oBM } \\
\left(n^{*}=187,693\right)\end{array}$ & $\begin{array}{l}\text { PCa w/BM } \\
\left(n^{*}=23,747\right)\end{array}$ \\
\hline $\begin{array}{l}\text { Supplementary classification of } \\
\text { factors influencing health status } \\
\text { and contact with health services } \\
\text { (V01-V91.9) }\end{array}$ & $17.0 \%$ & $18.7 \%$ \\
$\begin{array}{l}\text { Secondary malignant neoplasm } \\
\text { of other specified sites (198.xx) }\end{array}$ & $0.2 \%$ & $13.5 \%$ \\
$\begin{array}{l}\text { Diseases of the circulatory } \\
\text { system (390-459.9) }\end{array}$ & $3.1 \%$ & $6.1 \%$ \\
$\begin{array}{l}\text { Diseases of the genitourinary } \\
\text { system (580-629.9) }\end{array}$ & $2.7 \%$ & $5.2 \%$ \\
$\begin{array}{l}\text { Diseases of the respiratory } \\
\text { system (460-519.9) }\end{array}$ & $2.2 \%$ & $4.5 \%$ \\
$\begin{array}{l}\text { Diseases of the digestive system } \\
\text { (520-579.9) }\end{array}$ & $1.2 \%$ & $3.5 \%$ \\
$\begin{array}{l}\text { Injury and poisoning } \\
\text { (800-999.9) }\end{array}$ & $1.2 \%$ & $2.6 \%$ \\
$\begin{array}{l}\text { Symptoms, signs, and ill-defined } \\
\text { conditions (780-799.9) } \\
\text { Other }\end{array}$ & $1.0 \%$ & $2.5 \%$ \\
\hline
\end{tabular}

$P C a$ prostate cancer, $w / B M$ with bone metastases, $w / o B M$ without bone metastases, $S D$ standard deviation

( $P$ value for all: $<0.0001$ except primary admitting diagnosis for which no statistical comparisons were made)

* $N$ represents the number of hospitalizations among the sample of PCa patients treated in an inpatient and/or outpatient setting and does not represent the number of unique patients

${ }^{\dagger}$ Other primary admitting diagnoses include, but are not limited to, diseases of the musculoskeletal system and connective tissue (710-739.9), infectious and parasitic diseases (001-139.8), and diseases of blood and blood-forming organs (280-289.9)

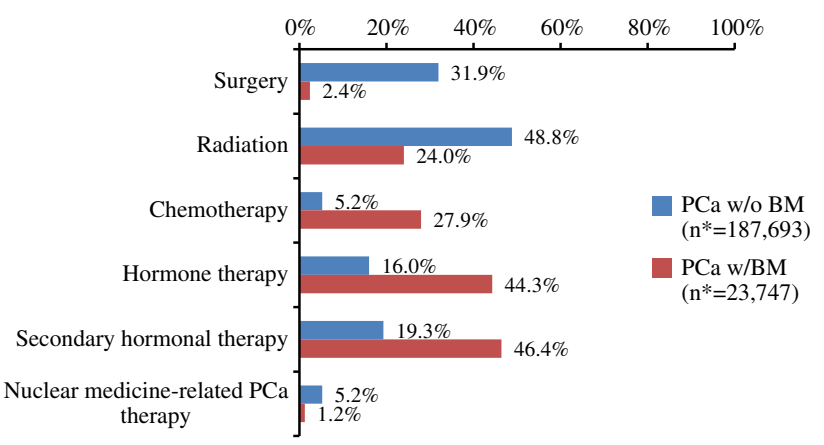

Fig. 1 Treatment utilization by hospital encounter: inpatient stays and outpatient visits. All comparisons were $P<0.0001$. $* N$ represents the number of hospitalizations among the sample of $\mathrm{PCa}$ patients treated in an inpatient and/or outpatient setting and does not represent the number of unique patients. $P C a$ prostate cancer, $w / B M$ with bone metastases, $w / o B M$ without bone metastases

Our primary variables of interest were treatments utilized within the encounter, corresponding costs, and LOS. Results showed that men w/BM were 1.5 times more likely to be treated in an inpatient setting compared with men 


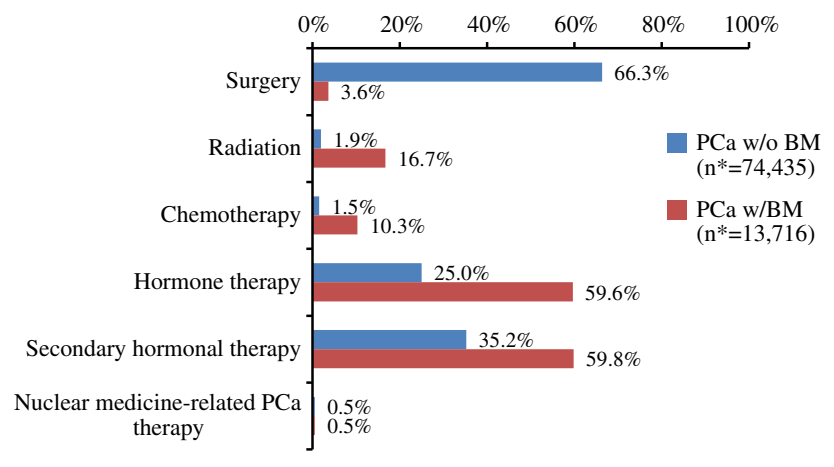

Fig. 2 Treatment utilization by hospital encounter: inpatient stays only. All comparisons were $P<0.0001$, except for nuclear medicine $(P=0.0164) .{ }^{*} N$ represents the number of hospitalizations among the sample of PCa patients treated in an inpatient setting and does not represent the number of unique patients. $P C a$ prostate cancer, $w / B M$ with bone metastases, $w / o B M$ without bone metastases

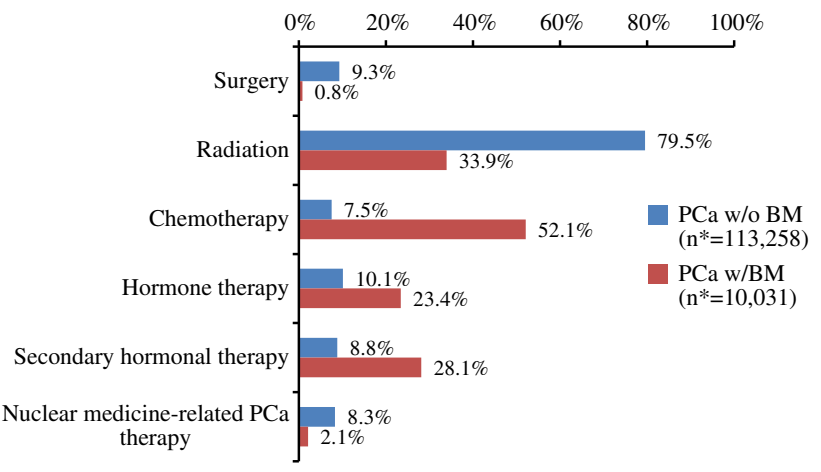

Fig. 3 Treatment utilization by hospital encounter: outpatient visits only. All comparisons were $P<0.05$. $* N$ represents the number of hospitalizations among the sample of PCa patients treated in an outpatient setting and does not represent the number of unique patients. $P C a$ prostate cancer, $w / B M$ with bone metastases, $w / o B M$ without bone metastases

w/oBM (57.8-39.7\%). These results underscore the medical instability of men w/BM, which is also confirmed by evaluating the nature of inpatient hospitalizations across the two groups. When men w/oBM were hospitalized, elective-type admissions were most common, indicating that many procedures/visits were scheduled in advance and patients were medically stable. Men w/BM were significantly more likely to have emergency department or urgent admissions, likely demonstrating lower disease stability. This finding may have impacted the cost difference between the two study groups, as costs associated with inpatient encounters were significantly higher in men w/BM. Almost $40 \%$ of the total cost was due to a longer LOS (4 additional days) and associated inpatient pharmacy costs. The inpatient LOS across the entire cohort of men was 4 days, similar to previous estimates [23].

When men w/oBM were admitted to the hospital, surgery was the most common procedure, occurring in two out of every three hospital stays. This finding is also consistent with Milenkovic et al. [22], where the most common procedures were RPs and TURPs. In contrast, men w/BM treated in the inpatient setting generally received primary/ secondary hormonal therapy. In the outpatient treatment setting, men w/oBM were more likely to have RT, while men w/BM were more likely to have chemotherapy. These findings are consistent with the current treatment paradigms for PCa $[4,17]$.

Studies on the economic burden of CRPC are limited, particularly from a hospital perspective, so our study sought to provide a more granular evaluation of these services. Given changes in the treatment landscape with CRPC, our primary interests were surgery, RT, chemotherapy, and radiopharmaceuticals. Prostatectomy procedures were the most commonly occurring surgery (average US\$3,027), while docetaxel was the most prevalent chemotherapy (average US\$2,197). Radiation procedures, particularly brachytherapy-related procedures (US $\$ 1,846$ ), were also more commonly seen in this group, with the majority of procedures done in a hospital-based outpatient setting. Additionally, the most common radiopharmaceuticals administered at outpatient visits in men w/oBM were iodine- 125 and palladium, which contributed to high costs of therapy in this setting. This finding was supported by the literature, as these are common, permanent, low-dose rate radiopharmaceuticals used in this population [1]. Radiopharmaceuticals are also an option for patients with multifocal bone pain, particularly if they are no longer candidates for effective chemotherapy [18]. Unlike previous findings, ${ }^{89} \mathrm{Sr}$ and ${ }^{153} \mathrm{Sm}$ ( $\beta$-emitting agents) were not the two most commonly used radiopharmaceuticals in our sample. Both can cause myelosuppression, limiting their use in patients with compromised bone marrow reserves, and may prevent future administration of chemotherapy. Radium-223, an $\alpha$-emitting radiopharmaceutical, targets bone metastases with high-energy, short-range irradiation [20]. This characteristic mechanism spares bone marrow as a result of lower penetration to surrounding tissues and limits toxic effects compared with traditional $\beta$-emitting radiopharmaceuticals [20]. A phase III, randomized, double-blind, placebo-controlled study $(N=921)$ evaluated the efficacy and safety of radium-223. OS, the primary endpoint, was significantly increased with radium-223 compared with placebo (14.9 vs. 11.3 months; $P=0.00007)$. Time to first SRE, the key secondary endpoint, was significantly delayed (median time to SRE 12.2 vs. 6.7 months, respectively; $P<0.0001$ ) [23]. These benefits may result in quick incorporation of radium-223 into clinical practice and guidelines for CRPC.

Although this assessment attempts to provide a granular evaluation of common CRPC treatments utilized in the hospital setting, hospital decision makers should view this 
Table 2 Treatment costs per encounter

\begin{tabular}{|c|c|c|c|c|c|c|}
\hline \multirow{2}{*}{$\begin{array}{l}\text { Standard billing } \\
\text { department codes }\end{array}$} & \multicolumn{3}{|l|}{$\mathrm{PCa}$ w/oBM } & \multicolumn{3}{|l|}{$\mathrm{PCa} w / \mathrm{BM}$} \\
\hline & $\begin{array}{l}\text { Inpatient } \\
(n=74,435) \\
\text { Mean (SD) }\end{array}$ & $\begin{array}{l}\text { Outpatient } \\
(n=113,258) \\
\text { Mean (SD) }\end{array}$ & $\begin{array}{l}\text { Total } \\
(N=187,693) \\
\text { Mean (SD) }\end{array}$ & $\begin{array}{l}\text { Inpatient } \\
(n=13,716) \\
\text { Mean (SD) }\end{array}$ & $\begin{array}{l}\text { Outpatient } \\
(n=10,031) \\
\text { Mean (SD) }\end{array}$ & $\begin{array}{l}\text { Total } \\
(N=23,747) \\
\text { Mean (SD) }\end{array}$ \\
\hline Total costs (US\$) & $\$ 11,944(13,245)$ & $\$ 4,422(7,127)$ & $\begin{array}{l}\$ 7,405 \\
\quad(10,666)\end{array}$ & $\$ 14,145(17,502)$ & $\$ 3,688(5,322)$ & $\begin{array}{l}\$ 9,728 \\
\quad(14,682)\end{array}$ \\
\hline $\begin{array}{l}\text { Professional/ } \\
\text { administrative fees }\end{array}$ & $\$ 233(1,499)$ & $\$ 59(282)$ & $\$ 128(973)$ & $\$ 281(1,289)$ & $\$ 146(349)$ & $\$ 224(1,008)$ \\
\hline Ambulance & $\$ 4(143)$ & $\$ 0(7)$ & $\$ 1(90)$ & $\$ 8(114)$ & $\$ 0(10)$ & $\$ 5(87)$ \\
\hline Surgery & $\$ 3,692(3,691)$ & $\$ 553(1,514)$ & $\$ 1,798(3,024)$ & $\$ 813(1,868)$ & $\$ 155(842)$ & $\$ 535(1,556)$ \\
\hline Audiology & $\$ 0(7)$ & $\$ 0(0)$ & $\$ 0(4)$ & $\$ 0(6)$ & $\$ 0(0)$ & $\$ 0(5)$ \\
\hline Blood bank & $\$ 202(664)$ & $\$ 4(72)$ & $\$ 83(433)$ & $\$ 466(1,342)$ & $\$ 34(245)$ & $\$ 284(1,054)$ \\
\hline Cardiology & $\$ 124(623)$ & $\$ 17(1,982)$ & $\$ 60(1,590)$ & $\$ 149(521)$ & $\$ 7(264)$ & $\$ 89(437)$ \\
\hline Central supply & $\$ 2,025(3,484)$ & $\$ 287(2,204)$ & $\$ 976(2,910)$ & $\$ 912(3,463)$ & $\$ 49(578)$ & $\$ 548(2,692)$ \\
\hline Diagnostic & $\$ 287$ (779) & $\$ 245$ (777) & $\$ 262(778)$ & $\$ 933(1,494)$ & $\$ 71(275)$ & $\$ 569(1,226)$ \\
\hline Dialysis & $\$ 34(476)$ & $\$ 0(10)$ & $\$ 14(300)$ & $\$ 67(652)$ & $\$ 0(26)$ & $\$ 39$ (497) \\
\hline $\begin{array}{l}\text { Durable medical } \\
\text { equipment }\end{array}$ & $\$ 95(697)$ & $\$ 4(74)$ & $\$ 40(445)$ & $\$ 61(538)$ & $\$ 4(196)$ & $\$ 37$ (429) \\
\hline Emergency room & $\$ 93(224)$ & $\$ 5(68)$ & $\$ 40(157)$ & $\$ 274$ (309) & $\$ 13(92)$ & $\$ 164(275)$ \\
\hline All home health & $\$ 0(36)$ & $\$ 0(32)$ & $\$ 0(34)$ & $\$ 8(873)$ & $\$ 2(90)$ & $\$ 5(666)$ \\
\hline Laboratory & $\$ 353(3,668)$ & $\$ 20(70)$ & $\$ 152(2,317)$ & $\$ 672(862)$ & $\$ 60(120)$ & $\$ 413$ (726) \\
\hline Nuclear medicine & $\$ 50(431)$ & $\$ 421(2,485)$ & $\$ 274(1,958)$ & $\$ 134$ (466) & $\$ 96(842)$ & $\$ 118(652)$ \\
\hline Pathology & $\$ 165(234)$ & $\$ 7(60)$ & $\$ 69(173)$ & $\$ 64(229)$ & $\$ 2(45)$ & $\$ 38(179)$ \\
\hline Pharmacy & $\$ 894(2,545)$ & $\$ 326(1,528)$ & $\$ 551(2,014)$ & $\$ 1,760(3,462)$ & $\$ 2,369(4,965)$ & $\$ 2,017(4,175)$ \\
\hline Rehabilitation & $\$ 125(543)$ & $\$ 1(21)$ & $\$ 50(348)$ & $\$ 332(831)$ & $\$ 3(37)$ & $\$ 193(653)$ \\
\hline Psychiatry & $\$ 4(568)$ & $\$ 0(4)$ & $\$ 2(357)$ & $\$ 3(175)$ & $\$ 0(10)$ & $\$ 2(133)$ \\
\hline Radiation therapy & $\$ 61(2,477)$ & $\$ 2,471(5,354)$ & $\$ 1,515(4,596)$ & $\$ 383(2,318)$ & $\$ 674(1,895)$ & $\$ 506(2,154)$ \\
\hline Respiratory therapy & $\$ 176(882)$ & $\$ 1(16)$ & $\$ 70(562)$ & $\$ 266(1,386)$ & $\$ 2(26)$ & $\$ 154(1,061)$ \\
\hline Room and board & $\$ 3,327(6,297)$ & $\$ 1(49)$ & $\$ 1,320(4,287)$ & $\$ 6,558(9,251)$ & $\$ 2(65)$ & $\$ 3,788(7,740)$ \\
\hline
\end{tabular}

$P C a$ prostate cancer, $S D$ standard deviation, $w / B M$ with bone metastases, $w / o B M$ without bone metastases

study as providing a baseline understanding of where future patterns of care will be derived. Recently approved treatments, such as abiraterone acetate, sipuleucel-T, enzalutamide, denosumab, and cabazitaxel [4], as well as radiopharmaceutical radium-223, are not captured in this assessment. The recent entries of these products limit our ability to evaluate their current utilization and costs. It will be imperative for decision makers to understand the incremental costs and benefits associated with these agents as new treatment patterns emerge.

Although no cost information exists for radium-223 and enzalutamide, decision makers can assess the cost and resulting cost effectiveness for these agents. On the basis of survival gains in a $\mathrm{PCa}$ population and pricing for individual treatments, docetaxel appears to be the most cost effective agent, with sipuleucel-T being the least cost effective [8, 11, 13]. The incremental survival benefit of abiraterone, radium-223, enzalutamide, and sipuleucel-T must be considered from a willingness-to-pay perspective; thus, a net-benefit analysis or model should be conducted once all information is available. Additionally, several treatments (e.g., RT) may be decreased as a result of these agents, which would offset product-specific costs. This premise of cost offsets may be of extreme importance to medical decision makers. A recent study of men with PCa indicated that the highest treatment cost was observed in patients who initially had RT. On average, their total costs were US\$42,554, with half of these costs due to outpatient resource utilization [24]. Our study supports these findings as well, as RT was one of the more common treatments evaluated within the context of this paper.

A greater focus on the cost effectiveness of treatments for $\mathrm{PCa}$, both in the inpatient and outpatient settings, will be an important consideration for healthcare decision makers. As RT has been identified as a high-cost treatment, it would be beneficial for medical decision makers to further analyze ways to offset associated services and costs 


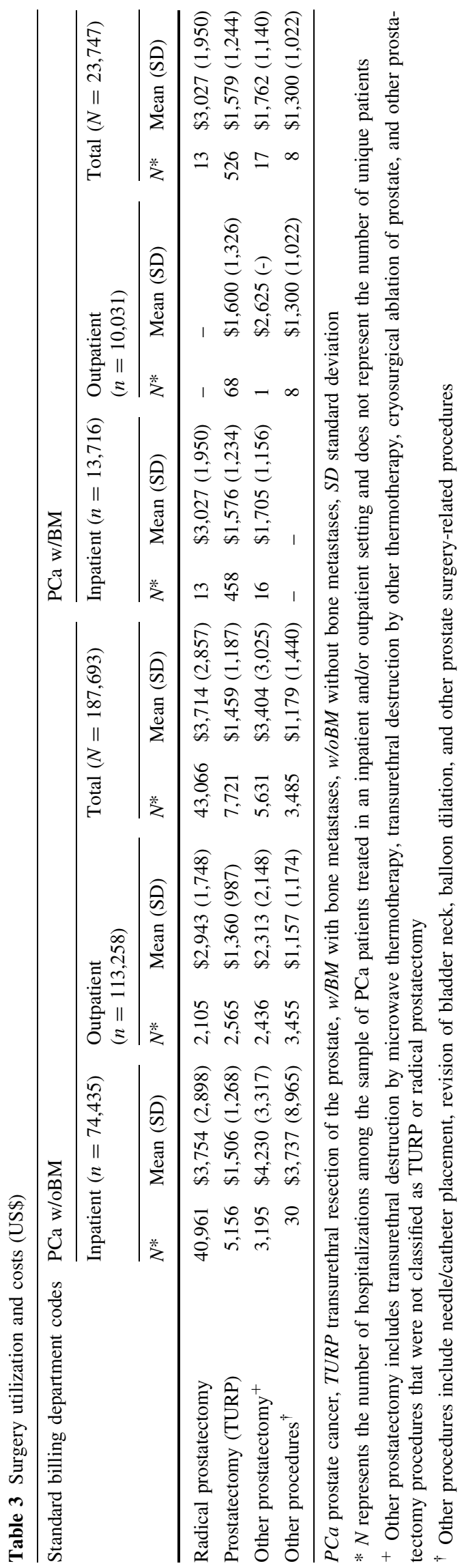

while maximizing patient survival and outcomes. With the abundance of newer agents recently approved and in the research pipeline, determining the most cost-effective strategy through empirical research will be the primary goal for all stakeholders, including patients.

\section{Strengths and Limitations}

This study has several strengths and limitations. First, this was a retrospective hospital claims analysis, which limits the amount of clinical information available (e.g., tumor stage, chief complaint), which would be valuable to stratify treatments on the basis of relevant risk groups. Additional detail or utilization occurring outside of this setting is not available and may also be useful in further describing the cohorts. Further studies investigating such clinical information may provide information regarding variables that drive admission between patients with w/BM and w/oBM. Furthermore, the differences reported here between these two cohorts (w/BM vs. w/oBM) may not be fully attributable to bone metastases status because of other differences between the two cohorts that may not have been measured. Secondly, a common limitation in studies such as ours that use an administrative healthcare database is selecting claims on the basis of ICD-9 codes. As such, there is potential for misclassification of patients. However, our analysis included a total of 211,440 encounters, which produced a good sample for evaluation. The mean age was 73 years in men w/BM and 69 years in men w/oBM in our study, which corresponds well to the overall PCa population (mean age of diagnosis for $\mathrm{PCa}$ is 67 years according to the most recent Survival, Epidemiology, and End Results [SEER] data) [3]. This similarity in demographics is thought to give our analysis good generalizability to the overall $\mathrm{PCa}$ population. However, two-thirds of the encounters in our study were in Caucasian men, while African American men represented approximately $10 \%$ of patients. Previous studies have demonstrated that $\mathrm{PCa}$ disproportionately affects African American men and, worldwide, African American men have the highest incidence of $\mathrm{PCa}$ $[25,26]$. Therefore, the difference in racial demographics in our population compared with the general PCa population could be considered a limitation. The majority of men in our analysis were treated in urban non-teaching hospitals, whereas CRPC patients are generally referred to teaching hospitals or cancer treatment centers. Hence, our sample may not be fully representative of the clinical practices of $\mathrm{PCa}$, as most hospitals participating in the Premier Perspective Database are predominantly small- to medium-sized non-teaching facilities serving a largely urban population. 


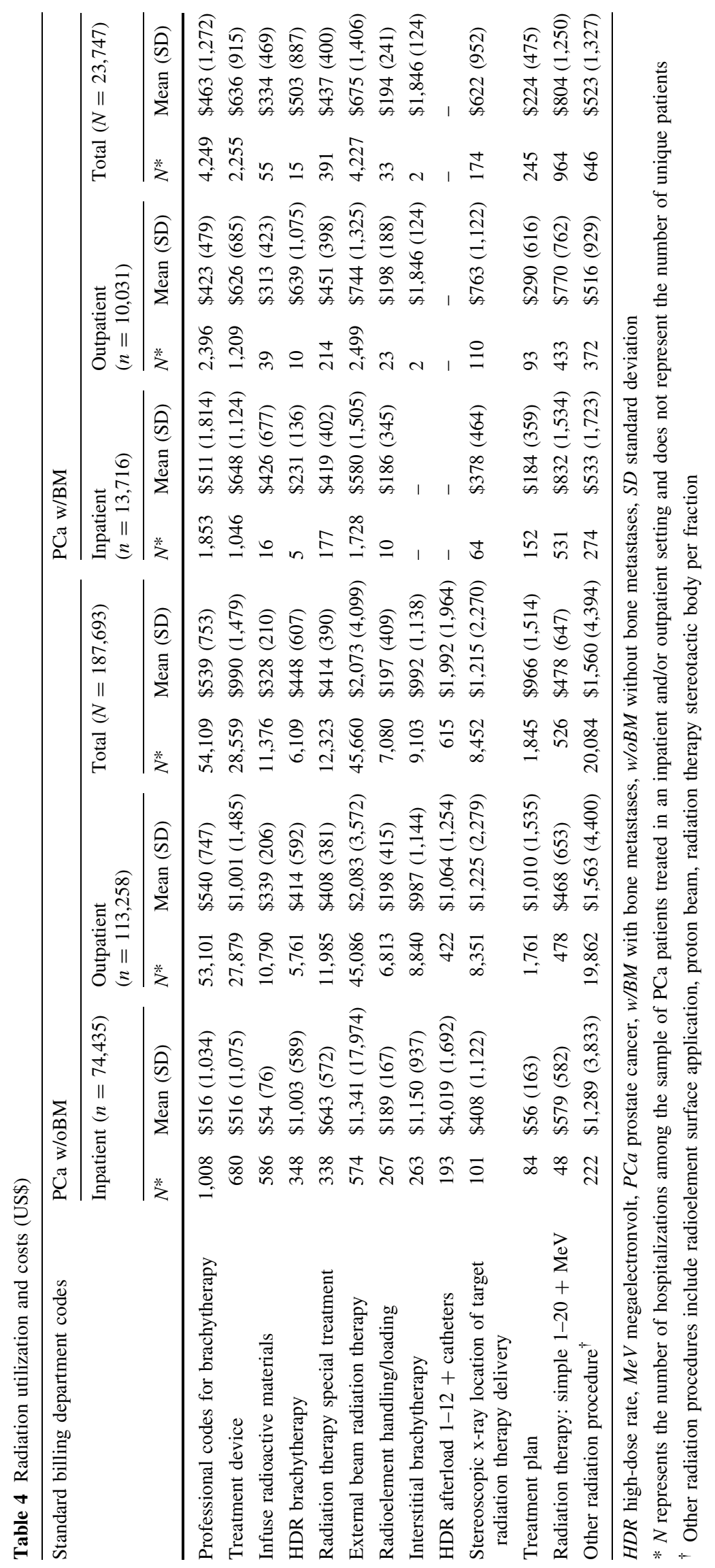




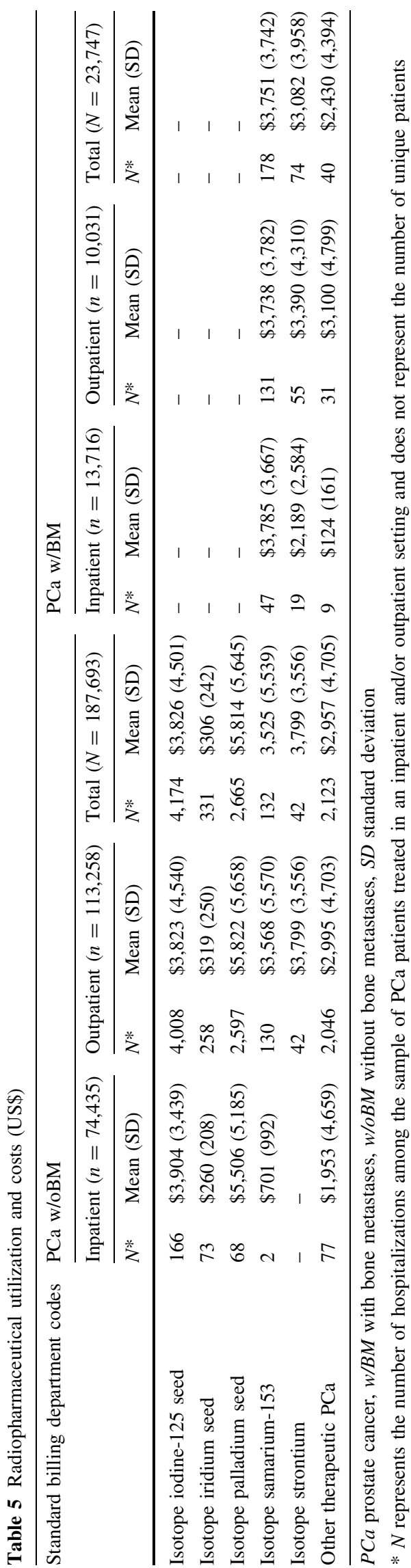

\section{Conclusions}

Costs and utilization of PCa-related treatments vary on the basis of the presence of metastases and treatment setting (inpatient vs. outpatient). As new treatment patterns in $\mathrm{PCa}$ evolve, decision makers and clinicians will continue to pay close attention to utilization of healthcare resources. Our study provides detailed information on utilization of healthcare resources in patients with PCa from a nationally representative hospital database to help inform the conversation about healthcare resource utilization and emerging treatment patterns.

Acknowledgments Bayer HealthCare Pharmaceuticals provided funding to Xcenda, a consulting company, to assist in the completion of this research. Authors Zagadailov, Farrelly, and Eaddy are employees of Xcenda and were not directly compensated by Bayer Healthcare Pharmaceuticals for their research. Drs. Sullivan, Ramsey, Asche, Shermock, and Sarma are paid consultants to Bayer. Brian Seal is an employee of Bayer.

Author Contributions All authors contributed to the conception of the study, the design of the study, the interpretation of the data, and writing of the manuscript. Brian Seal, Michael Eaddy, Eileen Farrelly, and Erin Zagadailov contributed to the assembly of the data and data analysis. Dr. Michael Eaddy is the guarantor of this research.

Open Access This article is distributed under the terms of the Creative Commons Attribution Noncommercial License which permits any noncommercial use, distribution, and reproduction in any medium, provided the original author(s) and the source are credited.

\section{References}

1. American Cancer Society. Cancer Facts \& Figures 2012. http:// www.cancer.org/Research/ CancerFactsFigures/index. Accessed 3 Aug 2012.

2. Siegel R, Naishadham D, Jemal A. Cancer statistics. CA Cancer J Clin. 2012;62:10-29.

3. Howlader N, Noone AM, Krapcho M (eds) et al. SEER Cancer Statistics Review, 1975-2009. National Cancer Institute. Bethesda, MD, http://seer.cancer.gov/csr/1975_2009_pops09/. Based on November 2011 SEER data submission, posted to the SEER website, 2012.

4. National Comprehensive Cancer Network (NCCN) Practice Guidelines in Oncology ${ }^{\mathrm{TM}}$. Prostate cancer, v3.2012. NCCN. http://www.nccn.org. Accessed 3 Aug 2012.

5. Edge SB, Byrd DR, Compton CC, Fritz AG, Greene FL, Trotti A, editors. Prostate. AJCC Cancer Staging Manual 7th ed. New York, NY: Springer; 2010.

6. Higano CS, Crawford ED. New and emerging agents for the treatment of castration-resistant prostate cancer. Urol Oncol. 2011;29(Suppl 6):S1-8.

7. Chi KN, Bjartell A, Dearnaley D, et al. Castration-resistant prostate cancer: from new pathophysiology to new treatment targets. Eur Urol. 2009;56:594-605.

8. de Bono JS, Oudard S, Ozguroglu M, et al. Prednisone plus cabazitaxel or mitoxantrone for metastatic castration-resistant prostate cancer progressing after docetaxel treatment: a randomised open-label trial. Lancet. 2010;376:1147-54. 
9. de Bono JS, Logothetis CJ, Molina A, et al. Abiraterone and increased survival in metastatic prostate cancer. $\mathrm{N}$ Engl $\mathrm{J}$ Med. 2011;364:1995-2005.

10. Scher HI, Fizazi K, Saad F, et al. Increased survival with enzalutamide in prostate cancer after chemotherapy. N Engl J Med. 2012;367:1187-97.

11. Kantoff PW, Higano CS, Shore ND, et al. Sipuleucel-T immunotherapy for castration-resistant prostate cancer. N Engl J Med. 2010;363(5):411-22.

12. Ryan CJ, de Bono JS, Molina A, et al. Interim analysis (IA) results of COU-AA-302, a randomized, phase 3 study of abiraterone acetate (AA) in chemotherapy-naïve patients (pts) with metastatic castration-resistant prostate cancer (mCRPC). Presented at: American Society of Clinical Oncology (ASCO); May 31-June 4, 2012; Chicago, IL.

13. Red Book Online. Micromedex 2.0, Truven Health Analytics, Inc. Accessed 11 Dec 2012.

14. Scher HI, Halabi S, Tannock I, et al. Design and endpoints of clinical trials for patients with progressive prostate cancer and castrate levels of testosterone: recommendations of the Prostate Cancer Clinical Trials Working Group. J Clin Oncol. 2008;26:1148-59.

15. Zelefsky MJ, Eastham JA, Sartor OA, et al. Cancer of the prostate. In: DeVita VT Jr, Lawrence TS, Rosenberg SA, editors. DeVita, Hellman, and Rosenberg's Cancer Principles \& Practice of Oncology, vol. 2, 8th ed. Philadelphia, PA: Lippincott Williams \& Wilkins and Wolters Kluwer. 2008. p 1392-1452

16. Scher HI, Morris MJ, Basch E, et al. Endpoints and outcomes in castration-resistant prostate cancer: from clinical trials to clinical practice. J Clin Oncol. 2011;29:3695-704.

17. Konski A, James J, Hartsell W, et al. Economic analysis of radiation therapy oncology group 97-14: multiple versus single fraction radiation treatment of patients with bone metastases. Am J Clin Oncol. 2009;32:423-8.
18. Janjan N, Lutz ST, Bedwinek JM, et al. Therapeutic guidelines for the treatment of bone metastasis: a report from the American College of Radiology Appropriateness Criteria Expert Panel on Radiation Oncology. J Palliat Med. 2009;12:417-26.

19. Pandit-Taskar N, Batraki M, Divgi CR. Radiopharmaceutical therapy for palliation of bone pain from osseous metastases. J Nucl Med. 2004;4:1358-65.

20. Nilsson S, Franzén L, Parker C, et al. Bone-targeted radium-223 in symptomatic, hormone-refractory prostate cancer: a randomised, multicentre, placebo-controlled phase II study. Lancet Oncol. 2007;8(7):587-94.

21. de Bono JS, Fizazi K, Saad F, et al. Phase 3 trial (AFFIRM) of enzalutamide (MDV3100), an androgen receptor signaling inhibitor: primary, secondary, and quality-of-life endpoint results. Presentation presented at: American Society of Clinical Oncology (ASCO); May 31-June 4, 2012; Chicago, IL.

22. Milenkovic M, Russo CA, Elixhauser A. Hospital stays for prostate cancer, 2004. Healthcare Cost and Utilization Project. Statistical Brief \#30. May 2007.

23. Parker C, Nilsson S, Heinrich D, et al. Updated analysis of the phase III, double-blind, randomized, multinational study of radium-223 chloride in castration-resistant prostate cancer (CPRC) patients with bone metastases (ALSYMPCA). Presented at: American Society of Clinical Oncology (ASCO); May 29June 2, 2009; Orlando, FL.

24. Crawford ED, Black L, Eaddy M, Kruep EJ. A retrospective analysis illustrating the substantial clinical and economic burden or prostate cancer. Prostate Cancer Prostatic Dis. 2010;13:162-7.

25. Hoffman RM, Gilliland FD, Eley JW, et al. Racial and ethnic differences in advanced-stage prostate cancer: the prostate cancer outcomes study. J Natl Cancer Inst. 2001;93:388-95.

26. Jones J. African-Americans and prostate cancer: why the discrepancies? J Natl Cancer Inst. 2001;93:342-4. 